\title{
DISTURBANCE INTERACTIONS: Mountain Pine BeEtle \& BLISTER Rust IN Whitebark Pine
}

\author{
NANCY BOCKINO $\downarrow$ DANIEL B. TINKER $\downarrow$ DEPARTMENT OF BOTANY \\ UNIVERSITY OF WYOMING $\downarrow$ LARAMIE
}

\begin{abstract}
$\downarrow \quad$ INTRODUCTION
Whitebark pine (Pinus albicaulis Englem.) is a keystone species of many high elevation ecosystems in the Greater Yellowstone Ecosystem (GYE) and directly influence watershed quality by regulating snow accumulation and retention, facilitating regeneration after a disturbance, and stabilizing soil and rock on steep, harsh sites.
\end{abstract}

Historically, the principle source of cyclic tree mortality in whitebark pine ecosystems was the mountain pine beetle (MPB; Dendroctonus ponderosae Hopk.). Periodic epidemics of bark beetles result in widespread tree mortality and are an important component of stand dynamics. The current beetle activity in the Greater Yellowstone is at epidemic levels, driven by high densities of both susceptible host trees and beetles.

In contrast to the MPB, blister rust (Cronartium ribicola Fisch.) is an exotic pathogen and a continuous source of disturbance, rather than cyclic. Paramount to the influence of this fungus is a severe reduction in whitebark pine recruitment due to the loss of cone production and extensive damage to seedlings and saplings. Blister rust is continuing to spread throughout the GYE, and due to its perpetual presence, is considered the most damaging agent to whitebark pine.

Because the current decline of whitebark is unprecedented, my master's research seeks to quantify the interactions between blister rust and the MPB. It is not known how the following variables influence this species' susceptibility to the MPB: 1) presence of an alternate host, specifically lodgepole pine (Pinus contorta var. latifolia); 2) severity of white pine blister rust; or 3) variable whitebark pine density due to diffusion by nonalternate host species. An enhanced understanding of these questions could support successful preservation strategies for this critical and charismatic high elevation conifer.

\section{$\downarrow$ RESEARCH PROJECT}

During the summer of 2006, I collected data from four study sites in the GYE with the help of two dedicated field assistants Michael Straw and Ryan Simms. Four sites were selected based on the presence of MPB and biophysical characteristics through the use of Forest Health Protection aerial surveys, personal field reconnaissance, and cooperation with National Forest and Park Service personnel.

At three of the four sites, two stand types were identified based on overstory conifer species composition. These different stand types assist in the determination of the roles tree density and a "diffusion-effect" by non-host species (Abies lasiocarpa Hook. and Picea engelmanni Parry.) play in the susceptibility of an individual whitebark pine to selection by the MPB within this sites. Blister rust was present on all three sites and in both stand types. The fourth study site, Sylvan Pass is dissimilar from 


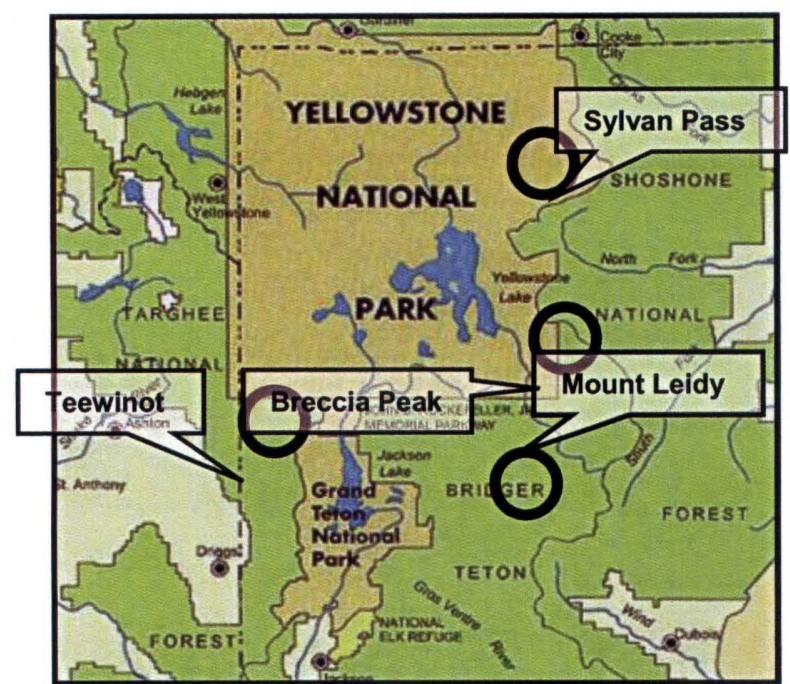

Figure 1. Map of collections sites in the Greater Yellowstone Ecosystem

the above three sites because blister rust is absent, and whitebark and lodgepole pine are growing in association as codominant canopy species. This site was examined to determine the role of host species in selection by the MPB.

At each stand, 24 temporary angle point sampling plots, using a metric basal area factor of 2.0, were systematically established to collect both tree and plot level data. Tree data collected included species, diameter at 1.3 meters, live or dead status, cone presence or absence, average number and size of pitch tubes, crown needle color, and blister rust severity (Six \& Newcomb 2005). Plot data included location, elevation, slope, aspect, and topographic position.

Data analysis incorporates several statistical techniques. Non-parametric chi-square analyses were utilized to test the statistical significance of the differences in frequency of a given characteristic (such as tree diameter and blister rust severity) for bivariate tabular data (SAS Institute, 2006). Selection ratios provide a probability of use for a specified host characteristic, and are calculated by determining the frequency of occurrence of MPB in habitat A compared to the frequency in habitat B (Manly et al. 1993). In this case, dissimilar MPB habitats are defined by individual whitebark pine host characteristics. For example, selection by MPB for whitebark pine with heavy blister rust was compared to the selection of trees with light blister rust. Selection ratio analyses complimented the chi-square analyses by accounting for stand density, species composition, epidemic intensity, and temporal sequence of attack. Logistic regression was used to describe a dichotomous discrete response (selection by MPB or not) as a function of tree and stand variables (Minitab Release 14.1, 2007).

\section{PRELIMINARY FINDINGS}

The overall condition of the whitebark stands sampled in this study provides a perspective on the severity of the disturbances currently impacting whitebark pine in the GYE. Roughly one half of the whitebark pine sampled in this study are dead, $70 \%$ have been attacked by MPB, and $85 \%$ have at least one blister rust symptom.

Our data provide evidence that at Sylvan Pass the MPB outbreak began in the whitebark pine, which were preferentially selected over lodgepole pine throughout the progression of the epidemic. In addition, beetle activity was greater in trees with greater blister rust severity. Therefore, we conclude that host tree species and blister rust severity influence individual tree selection by MPB.

\section{ACKNOWLEDGMENTS}

Funding sources include UWYO-NPS Research Grant, a joint Fire Science Grant \# H1200040001. Gracious support was received from Dan Tinker, Ken Gerow, David Legg, Cory Bolen, Bill Romme, and Kelly McCloskey.

\section{Literature Cited}

Manly, B.F.J., L.L McDonald. \& D.L. Thomas. 1993. Resource selection by animals. London: Chapman \& Hall.

Minitab, 2007. State College, Pennsylvania. Version 14.1.SAS Institute, 2006. Cary North Carolina, Version. 9.3.1.

Six, D.L. \& M. Newcomb. 2005. A rapid rating system for rating white pine blister rust incidence, severity and within-tree distribution in whitebark pine. Northwest Science, 79(2\&3):189-195. 